\title{
药 \\ PRIORIDADES PROGRAMÁTICAS E AGENDA LEGISLATIVA DO PARTIDO NOVO NA CÂMARA DOS DEPUTADOS EM 2019
}

\author{
PROGRAMMATIC PRIORITIES AND LEGISLATIVE AGENDA OF THE NOVO \\ PARTY IN THE CHAMBER OF DEPUTIES IN 2019
}

\section{PRIORIDADES PROGRAMÁTICAS Y AGENDA LEGISLATIVA PARA EL PARTIDO NOVO EN LA CÁMARA DE LOS DIPUTADOS EN 2019}

Paulo Cesar Gregorio ${ }^{1}$

\begin{abstract}
Resumo: Estudos sobre a funcionalidade de partidos e sistemas partidários que consideram as dimensões ideológica e programática da competição partidária, via congruência partidária, proporcionam uma melhor compreensão sobre a definição de agendas legislativas. Este trabalho permite analisar a congruência entre as prioridades temáticas, expressas nas cláusulas do Estatuto do partido NOVO, e sua agenda legislativa subsequente, fornecendo elementos auxiliadores para compreensão do grau de representatividade entre o Congresso e partido. Utilizamos a Análise de Conteúdo de todas as proposições dos oito deputados federais do partido, no mandato de 2019, a fim de identificar os temas mais recorrentes. Esta análise empírica corrobora com a hipótese de que o partido NOVO apresenta congruência partidária significativa, uma vez que seus parlamentares apresentam proposições que refletem as diretrizes programáticas priorizadas em seu Estatuto e Manifesto Partidário.
\end{abstract}

Palavras chave: Agenda Legislativa; Congruência; Partido NOVO; Prioridades Temáticas.

Abstract: Studies on the functionality of parties and party systems considering the ideological and programmatic dimensions of party competition, through party congruence, provide a better understanding of the definition of legislative agendas. This work makes it possible to analyze the congruence between the thematic priorities, expressed in the clauses of the NOVO party's Statute, and its subsequent legislative agenda, providing supporting elements for understanding the degree of representation between Congress and the party. We applied the Content Analysis methods to analyze the proposals of all eight NOVO federal deputies in the 2019 mandate, in order to identify recurring themes. This empirical analysis corroborates the hypothesis that the NOVO party has significant party congruence, since its parliamentarians present proposals that reflect the programmatic guidelines prioritised in its party's Statute and Manifesto.

Keywords: Legislative Agenda; Congruence; Party NOVO; Thematic Priorities.

Resumen: Los estudios sobre la funcionalidad de los partidos y los sistemas de partidos que consideran las dimensiones ideológicas y programáticas de la competencia de los partidos, a través de la congruencia de los partidos, proporcionan una mejor comprensión de la definición de las agendas legislativas. Este trabajo permite analizar la congruencia entre las prioridades temáticas, expresadas en las cláusulas del Estatuto del partido NOVO, y su agenda legislativa posterior, proporcionando elementos de apoyo para comprender el grado de representatividad entre el Congreso y el partido. Utilizamos el método de Análisis de Contenido de todas las propuestas de los ocho diputados federales del partido, en el mandato de 2019, para identificar los temas más recurrentes. Este análisis empírico corrobora la hipótesis de que el partido NOVO tiene una congruencia significativa entre los partidos, ya que sus parlamentarios presentan propuestas que reflejan las directrices programáticas presentes en su Estatuto y Manifiesto del partido.

\footnotetext{
${ }^{1}$ Mestrando em Ciência Política no Programa de Pós-Graduação em Ciência Política da Universidade Federal de São Carlos (PPGPol/UFSCar), com pesquisa financiada pela CAPES e vinculada à linha de pesquisa Instituições, Organizações e Comportamento Político. Bacharel em Administração Pública pela Faculdade de Ciências e Letras da Universidade Estadual Paulista (UNESP, campus Araraquara-SP). Participa do grupo de pesquisa Política Comparada, Organizações Partidárias, Eleições e Comportamento Político. ORCID: https://orcid.org/0000-00022901-1067. E-mail: pauloc.greco@gmail.com.
} 
Palabras clave: Agenda Legislativa; Congruência; Partido NOVO; Prioridades Temáticas.

\section{Introdução}

Existe uma variedade de estudos científicos, tanto teóricos quanto empíricos, que avaliam a diversidade e funcionalidade de partidos e sistemas partidários. Assim, considerar as dimensões ideológica e programática da competição partidária, em conteúdo substantivo, no estudo de partidos e sistemas partidários proporcionaria uma melhor compreensão dessa diversidade (RODRIGUEZ; MONTERO, 2002). Destacamos ainda, um notável consenso normativo na literatura que trata do tema sobre a relação entre partidos fortes, coerentes e coesos e o êxito das consolidações democráticas na América Latina (DIAMOND; HARTLYN; LINZ; LIPSET, 1999). Essas características indicam para a necessidade de uma unidade intrapartidária capaz de mobilizar e produzir alinhamento entre conteúdo ideológico e programático, a qual a literatura denomina coerência partidária.

Uma questão central para as democracias contemporâneas seria o alinhamento entre a promessa eleitoral e a ação governamental por relacionar o grau de responsividade de representantes políticos eleitos às demandas dos cidadãos (DAHL, 2015). Já os estudos sobre a formação e definição de agenda enfatizam o papel dos partidos políticos na construção de agendas, como centralizadores de temáticas de maior relevância, tanto relativas a questões recentes quanto em assuntos temáticos mais vantajosos ao partido (ALDRICH, 2011). A partir desses argumentos teóricos, uma análise do grau de congruência partidária dos membros dos partidos em suas posições ideológicas e programáticas fornece ferramentas para compreensão da funcionalidade dos partidos e sistemas partidários nas democracias recentes, principalmente em duas dimensões: responsividade de representantes políticos eleitos e congruência partidária.

No Brasil, os estudos empíricos relativos às instituições mais centrais, como governo e Legislativo, e com a mediação dos partidos políticos, contribuem para uma produção significativa do tema da representação, mas a partir de enfoques diferentes ao debate de estudos sobre congruência. Deste modo, esses trabalhos fornecem ferramentas que auxiliam na compreensão de alguns elementos como as preferências políticas, o posicionamento ideológico dos representantes, através de sua produção legislativa, embora não trate de compará-los diretamente com as preferências dos eleitores, que é o que caracteriza os estudos de congruência (CARRERÃO, 2015).

Durante as eleições os partidos fazem apelos aos eleitores, adotando posições em políticas públicas e enfatizando determinadas temáticas (EGAN, 2013; PETROCIK, 1996). Portanto, os partidos políticos são capazes de contribuir para a definição da agenda e seu impacto varia de acordo com o tipo de agenda e o momento, mas o conflito eleitoral se estabelece a partir da defesa e congruência de seus compromissos programáticos de campanha. Para Fagan (2018), a relação entre a plataforma e a agenda do Congresso varia de acordo com o 
assunto, tipo de agenda e alinhamento ao governo, indicando que políticas enfatizadas na plataforma do partido podem prever questões enfatizadas no Congresso, mas apenas imediatamente após a eleição presidencial. Deste modo, a análise da congruência entre a construção da agenda legislativa dos deputados de um partido em seu primeiro mandato para Câmara dos Deputados, como o partido NOVO, a partir de seu programa eleitoral, contribui para a compreensão dos fatores e elementos no debate que estabelece uma relação entre a existência de partidos políticos com um conteúdo programático e ideológico mais ou menos definido.

O objetivo central deste trabalho é descrever e analisar a congruência partidária entre as prioridades temáticas, expressas nas cláusulas do Estatuto do partido NOVO e a agenda subsequente dos oito deputados eleitos pelo partido (Adriana Ventura; Alexis Fonteyne; Gilson Marques; Lucas Gonzalez; Marcel Van Hattem; Paulo Ganime; Tiago Mitraud e Vinicius Poit), para a Câmara dos Deputados, compreendidas em seu primeiro ano de mandato de 2019. Os dados utilizados foram coletados diretamente na plataforma digital do Sigalei ${ }^{2}$, empresa especializada em monitoramento e tratamento de dados legislativos, considerando todas as proposições apresentadas pelos deputados do partido NOVO no período considerado.

Construímos um grupo de sete categorias temáticas a partir do Termo de Atuação e Compromisso Partidário, presentes no Estatuto do partido NOVO. A partir dessas categorias, empregamos uma classificação, através do método de Análise de Conteúdo, de todas as proposições dos deputados federais do partido, investigando o grau de congruência dessas duas dimensões (temáticas e agenda). Paralelo a esse objetivo analítico descritivo, o estudo deste trabalho contribui por dimensionar atitudes e valores na construção da agenda legislativa por uma parte da elite política, a partir do qual se sustentam os princípios da democracia representativa.

Após essa primeira parte introdutória de definição do objeto de pesquisa, na segunda parte deste trabalho, fornecemos uma síntese bibliográfica sobre o debate de representação, relacionando accountability, responsividade e congruência, que serve como suporte teórico para identificar nosso objeto de estudo e esclarecer a hipótese e os resultados verificados. Posteriormente, na terceira parte, explicamos a operacionalização metodológica dos dados, tanto para construção das categorias, a partir do Estatuto do partido Novo, quanto para a subsequente categorização das proposições legislativas, procedimentais e substantivas, através de Análise de Conteúdo. Na quarta parte, evidenciamos as principais descobertas de nosso trabalho através da discussão e apresentação dos dados empíricos. Na parte final apresentamos algumas conclusões e questionamentos, apontando alguns caminhos para novas pesquisas.

\footnotetext{
${ }^{2}$ Ressaltamos um agradecimento à equipe do Sigalei após a viabilização de uma conta de usuário e acesso ao seu portfólio e dados pelo período de construção deste trabalho, visando a aproximação entre o terceiro setor e a universidade (UFSCar) no sentido elucidar o papel do trabalho científico e o seu benefício para a sociedade.
} 


\section{Estudos sobre congruência: representação, accountability e responsividade}

A diversidade de estudos empíricos sobre a formação de agenda legislativa no Brasil contribui para a compreensão tanto dos arranjos institucionais nos diversos níveis do governo quanto do provimento de políticas responsivas que contribuem para a saúde da democracia representativa. Assim, os partidos políticos se configuram como um ator relevante na construção dessa agenda a partir de seus programas partidários ideológicos. $\mathrm{O}$ argumento de Rodriguez e Montero (2002) de que os partidos de América Latina são organizações que cumprem funções diferentes das dos partidos políticos ocidentais aponta para o movimento que levou à exclusão de determinadas questões da agenda dos investigadores e explicam a desatenção quase sistemática para as questões relacionadas com o programa e a ideologia dos partidos, em geral, e para o grau de congruência nas posturas programáticas e ideológicas dos membros dos partidos.

Com a consolidação dos sistemas partidários, após o processo de redemocratização na América Latina e, em especifico no caso brasileiro, a qual origina um sistema de partidos políticos identificável e institucionalizado, verifica-se o avanço no estudo substantivo de partidos políticos, que acarreta na discussão de dimensões, como a formação de agenda legislativa, disciplina partidária ${ }^{3}$ e a congruência político-partidária. Segundo Coppedge (1997), o foco principal desses estudos na América Latina priorizou dimensões como a volatilidade, a fragmentação, o número efetivo de partidos, entre outras, que favorecem a análise comparativa entres esses sistemas partidários, ao invés de uma discussão acerca de aspectos problemáticos como o são o programa e a ideologia dos partidos.

Ao considerarmos as democracias recentes como partidárias, devemos considerar a importância do estabelecimento de agendas no processo político. Assim, os partidos políticos seriam os responsáveis por mobilizar e determinar as prioridades das legislaturas, elaborando um programa de governo exequível. Durante as eleições, os partidos enfatizam questões, adotando posições que estabelecem uma relação de apelo aos eleitores (EGAN, 2013; PETROCIK, 1996), a fim de potencializar a identificação entre as temáticas programáticas do partido às defesas de interesses individuais dos eleitores no processo de decisão eleitoral. Portanto, os programas de governo poderiam ser entendidos como mecanismos pelos quais se vincula eleitores aos representantes eleitos, ou seja, caso os partidos nos governos não representem as prioridades prometidas, o conflito eleitoral entre os partidos não estruturaria o conflito político no governo sobre as agendas políticas (FAGAN, 2018).

\footnotetext{
${ }^{3}$ A contribuição de Figueiredo e Limongi, expressa por meio de uma série de artigos (1995b; 1996a; 1996b; 1997; 1998a; 1998b), está em caracterizar o que os autores chamam de "bases institucionais do presidencialismo de coalizão", evidenciando o grau de disciplina dos partidos.
} 
Apesar da discussão sobre representação política ser amplamente explorada no Brasil, existe uma necessidade cada vez maior em se discutir e avaliar em que medida as ações políticas dos parlamentares expressam efetivamente um alinhamento e representação com o eleitorado. Tal enfoque de análise empírica sobre representação política caracteriza-se por um estudo de congruência político partidária cuja ideia central que norteia e justifica esses estudos é a de que na democracia representativa se espera que os representantes sejam responsivos a preferências, opiniões ou interesses dos cidadãos (CARRERÃO, 2015). As preferências e decisões dos representantes, atuando como policy makers, via construção de agenda legislativa por proposições parlamentares ${ }^{4}$, estabelece um vínculo com a decisão do eleitor sobre quem eleger, entre a escolha de diferentes programas de políticas.

Para Anthony Downs (1957), uma das principais referências da Teoria da Competição Partidária, o aspecto mais significativo dos partidos políticos é que eles formulam políticas com o intuito de ganhar eleições, sendo as ideologias vistas como um meio para se chegar ao poder. Assim, os atores políticos comportam-se racionalmente a fim de atingir seus objetivos, similarmente a agentes econômicos em um mercado. John Aldrich (2011), assim como Downs, filia-se à perspectiva da escolha racional. Contudo, no novo institucionalismo de Aldrich a obtenção de cargos seria apenas um dos objetivos dos políticos profissionais e ao agir expressando valores e preferências, os políticos formulariam e moldariam a agenda de seus partidos.

Outra contribuição de Aldrich (2011) no campo da teoria da competição partidária foi considerar o papel dos militantes partidários, que constrangem os líderes do partido e seus candidatos. Os militantes na teoria espacial são motivados por políticas e suas ações são movidas pelas suas preferências sobre o plano de governo. Assim, o seu comportamento de voto é determinado por suas percepções de quais candidatos parecem mais dispostos a fazer o que esses cidadãos acreditam ser o melhor. Uma vez eleitos, os políticos devem defender no governo posições congruentes com a plataforma eleitoral e ideológica de seu partido.

De fato, o estudo sobre comportamento partidário foi cada vez mais influenciado pela tradição da escolha racional na Ciência Política, fornecendo alguns modelos de análise que pressupõem os partidos com um conjunto pequeno e bem definido de objetivos. O trabalho de Strom e Müller (1999) desenvolve uma descrição comportamental mais geral dos partidos políticos competitivos, mantendo a premissa de que os líderes partidários atribuem valor à três esferas diferentes: votes, office e policy. Nesse cenário, os autores distinguem (1) office-seeking,

\footnotetext{
${ }^{4}$ Segundo o Regimento Interno da Câmara dos Deputados, proposição é toda matéria sujeita à deliberação da Câmara. Apesar dessa ampla definição, os tipos de proposição considerados principais, visto que originam as normas descritas no art. 59 da Constituição Federal, são: Propostas de Emenda à Constituição (PEC), Projetos de Lei Complementar (PLP), Projetos de Lei Ordinária (PL), Projetos de Decreto Legislativo (PDC), Projetos de Resolução (PRC) e Medidas Provisórias (MPV). Há ainda mais tipos de proposição apreciados pela Câmara, tais como: pareceres, emendas, propostas de fiscalização de controle, indicações, etc.
} 
(2) policy-seeking e (3) vote-seeking como três modelos independentes de comportamento partidário nos quais os líderes partidários se envolvem:

1. Os partidos no modelo office-seeking maximizam seu controle sobre os benefícios dos cargos políticos (office), ou seja, dos bens privados concedidos a destinatários com compromissos governamentais politicamente discricionários.

2. Os partidos policy-seeking buscam maximizar seu impacto nas políticas públicas (policy). Esse modelo deriva principalmente da teoria da coalizão e desafia especificamente a suposição de que todos os partidos são parceiros da coalizão igualmente viáveis, ou seja, que os partidos são indiscriminados em relação aos seus parceiros da coalizão.

3. Contribuindo com o argumento de Downs (1957) de que os partidos políticos buscam maximizar votes (membros), os partidos vote-seeking visam maximizar seu apoio eleitoral para controlar o governo, ou seja, "os partidos formulam políticas para vencer as eleições, em vez de vencer as eleições para formular políticas" (DOWNS, 1957, p. 28).

Para Strom e Müller (1999) os partidos políticos anseiam todos estes bens. Contudo, em muitas situações essas atividades entram em conflito e, em decorrência, uma mudança no comportamento partidário por meio de escolhas ou trocas (trade-offs) entre as esferas priorizadas. Com efeito, se estabelece um vínculo entre eleitores e partidos e se torna essencial compreender o tipo e sob quais circunstância ocorrem essas trocas (trade-offs). Isto porque para chegar ao poder os partidos oferecem aos eleitores uma plataforma programática. Nesse caso, os partidos são entendidos como office-seekers. Os eleitores, por sua vez, comparam as plataformas oferecidas pelos partidos e escolhem aquela que mais se aproxima de suas preferências, isto é, o eleitor se posiciona em uma escala de preferências, enquanto um policyseeker (DOWNS, 1957). Assim, devemos considerar que os eleitores atuam tanto em caráter seletivo, quando estabelecem uma escolha racional entre a melhor alternativa, quanto em caráter avaliativo, na medida em que avaliam o cumprimento dos compromissos dos candidatos nas eleições futuras.

O estrito procedimento de apresentar proposições na Câmara dos Deputados representa um baixo custo para seus atores, o qual Mayhew (1974) classifica como fugazes atos de advertisement (publicidade) ou position taking (tomada de posição). No entanto, os custos do processo decisório na atuação legislativa são elevados, envolvem consenso, por considerar, principalmente uma equação entre perdas e ganhos diante de quais temas serão inseridos na agenda, tornando-se proposições legislativas e, ao fim, culminando em políticas. Segundo Egan (2013), as questões mais salientes seriam aquelas advindas de um consenso, em um contexto de estabilidade, no qual as informações sobre as prioridades dos formuladores de políticas possuem 
maior relevância aos eleitores que o diagnóstico sobre o resultado dessas decisões. Assim, apesar da literatura que define agenda legislativa minimizar o papel dos partidos políticos (BAUMGARTNER; JONES, 1993), devemos considerar o papel fundamental dos partidos para o estabelecimento de prioridades em relação aos programas partidários.

Para além dos custos do processo decisório e de consenso, a combinação entre o fato do eleitor estabelecer suas preferências como policyseekers e dos partidos atuarem como officeseekers, segundo Hofferbert e Budge (1992), fomentaria uma maior responsividade ${ }^{5}$ aos eleitores. Deste modo, os eleitores avaliariam tanto as prioridades programáticas dos partidos políticos, expressas no período eleitoral, quanto o desempenho eleitoral evidenciado nas proposições legislativas, selecionando as boas políticas ou os políticos que sustentem boas políticas, no qual a plataforma partidária vencedora se torna o mandato ${ }^{6}$ que os governos buscam realizar (CARREIRÃO, 2015).

Nesse sentido, a relevância deste trabalho estaria nesta lacuna de compreender em que medida o alinhamento entre programa partidário e a posterior construção de agenda legislativa estabelece uma relação de congruência partidária e fornece ferramentas para analisar o debate entre a identificação de partidos com conteúdo programático e ideológico mais ou menos definidos. Para tanto, é necessário compreender a relação entre o conceito de representação, accountability e responsividade no qual supõe que os representantes tomam decisões considerando a emissão anterior de interesses dos eleitores. Assim, um governo responsivo adotaria políticas nas quais os cidadãos sinalizam como sendo relevantes (MANIN; PRZEWORSKI; STOKES, 1999).

De acordo com Carreirão (2015), as relações entre a representação através das eleições seriam compreendidas através de duas esferas, ou do ponto de vista do mandato ou da prestação de contas (accountability). Assim, a complexidade dessa relação deriva da relação de controle entre cidadãos e governos: por um lado os eleitores são incapazes de constranger governos a seguirem determinados mandatos, e do outro os eleitos poderiam ser controlados via mecanismos de prestação de contas, cuja reeleição seria o objetivo dos representantes como resultado de sucesso no alinhamento entre agenda e interesse dos cidadãos. Portanto, em um governo responsivo, sobre o viés da prestação de contas,

\footnotetext{
${ }^{5}$ Como a reeleição requer ratificação dos constituintes, os membros devem estar em posição de fornecer os tipos de benefícios com os quais os eleitores se preocupam. Sendo assim, para Mayhew (1974), responsividade significa que os legisladores sejam capazes de atender às necessidades e solicitações de seus constituintes.

${ }^{6}$ Observe-se que a representação por mandato é uma situação em que as políticas adotadas pelos representantes seguem suas plataformas eleitorais e essas políticas são as melhores para os cidadãos sob as condições observadas pelos representantes (MANIN; PRZEWORSKI e STOKES, 1999).
} 
[...] as eleições servem para manter o governo responsável pelos resultados de suas ações passadas. Por anteciparem o julgamento dos eleitores, os governantes são induzidos a escolher políticas, julgando que serão bem avaliadas pelos cidadãos no momento da próxima eleição (MANIN; PRZEWORSKI; STOKES, 2006, p. 105-106).

O trabalho seminal de David Mayhew - Congress: The Electoral Connection, publicado em 1974, sobre conexão eleitoral e Congresso destaca que o desenvolvimento institucional da Câmara deriva diretamente do interesse próprio de seus membros. A obra ressalta que o período pós-Segunda Guerra Mundial testemunhou uma expansão significativa do número de votações nominais no Congresso, fato que constrangeu os legisladores a aumentar sua participação em votações e, consequentemente, nas chances de que uma série de posições inconsistentes em votações nominais se tornassem custosas para a próxima eleição. Esse fenômeno, segundo Mayhew, contribuiu para que legisladores atuassem como meros "single-minded seekers of reelection" e, nesta busca persistente pela reeleição, utilizassem regularmente alguns tipos de atividades como a publicidade, a reivindicação de crédito e a tomada de posição. Assim, como componentes da concepção mayhewiana de incentivo eleitoral, os membros do Congresso, sempre que possível, se envolveriam em várias formas de tomada de posição de forma ambiciosa, autônoma e receptiva.

Nesse cenário, o conceito de representação se aproxima ao de responsividade e, consequentemente, se associa à ideia de causalidade com a congruência política. Assim, para Carreirão (2015), a análise de congruência política teria como referência as preferências manifestadas e não apenas os interesses, característica que possibilita uma vertente de estudos de verificação de correspondência entre opinião pública e opinião dos representantes, expressas pela construção da agenda e aprovação de políticas. Para o autor, embora haja uma vasta literatura, no Brasil, sobre comportamento parlamentar, tipo de produção legislativa e disciplina partidária, a lacuna nos estudos de congruência estaria em considerar as posições programáticas dos partidos como elemento de relevância para essa investigação.

Podemos destacar o trabalho de Tarouco e Madeira (2013), que analisa essas posições, através de uma vasta análise de conteúdo de documentos programáticos dos partidos políticos brasileiros, especialmente com a finalidade de identificar e classificar os partidos ideologicamente. Sendo assim, nosso trabalho desenvolve um ensaio sobre essa congruência partidária, ao analisar a congruência entre as prioridades temáticas, expressas nas cláusulas do Estatuto do partido NOVO, e a agenda legislativa subsequente do partido, fornecendo ferramentas para compreensão do grau de representatividade entre o Congresso e partidos brasileiros. 


\section{Categorização e Metodologia}

Para descrever e analisar a congruência entre as prioridades temáticas e a agenda legislativa subsequente do partido NOVO, utilizamos como critério metodológico verificar, entre todas as proposições do NOVO emitidas no mandato de 2019, o percentual daquelas que se referiam aos compromissos programáticos do partido.

A condução desta análise demandou o emprego do método de Análise de Conteúdo, uma vez que o conteúdo das proposições legislativas é comparado ao conteúdo dos compromissos programáticos do Estatuto do NOVO. Esta comparação permite a verificação de congruência entre uma determinada proposição e um determinado compromisso programático. Sua execução, contudo, é possível apenas após a definição de unidades de análise. Essas, assim como escolha das regras de contagem, e a escolha das categorias, constituem, de acordo com Bardin (2002), o processo de exploração do material em Análise de Conteúdo.

Para a escolha das unidades de análise o procedimento adotado foi o de tipo semântico, isto é, optamos por identificar e classificar segmentos temáticos em determinadas categorias. Trata-se de operações de desmembramento de um texto em unidades, para descobrir os diferentes núcleos de sentido que constituíram a comunicação. Este desmembramento resulta em fragmentos, que para Chizzotti (2006) podem ser palavras, termos ou frases significativas de uma mensagem. Precisamente, é o menor recorte de ordem semântica que se desprende do texto (BARDIN, 2002). A partir de uma perspectiva conceitual nos referimos à unidade de registro como nossa unidade de análise na Análise de Conteúdo.

De acordo com Bardin (2002), a importância de uma unidade de registro de classificação, como uma unidade temática, varia de acordo com sua frequência de aparição. Desse modo, os procedimentos metodológicos adotados foram desde a criação de categorias à identificação e contagem da frequência das mesmas. Não foram atribuídos pesos diferentes às categorias. Após verificar o número de aparições de cada uma, calculou-se a frequência da mesma.

A construção das categorias de análise foi elaborada a partir de uma avaliação do Programa Partidário e do Estatuto do partido NOVO. No Estatuto constam seis compromissos programáticos e de atuação legislativa, que expressam as diretrizes principais também identificadas no Manifesto. A partir deles foram criadas então seis categorias de análise "Gestão de Políticas Públicas"; "Redução de Privilégios"; "Capacitação e Transparência"; "Liberalismo Econômico"; "Sistema Político" e "Tributação", e uma categoria adicional "Outros", para classificar os casos em que o conteúdo programático das proposições não se enquadra em nenhuma das seis categorias.

Essas categorias são excludentes na medida em que as variáveis que as compreendem delimitam apenas os critérios para as quais servem de explicação. Assim, consideramos de salutar importância evidenciar as principais características e especificações de cada categoria de 
análise a partir do conjunto de informações presentes no Programa Partidário e do Estatuto do partido NOVO. A categoria "Gestão de Políticas Públicas" refere-se as proposições que estabelecem um conjunto de planos e metas exequíveis pelo Estado no curto, médio e longo prazo, integralmente àquelas vinculadas ou associadas as áreas de saúde, educação e infraestrutura.

A segunda categoria "Redução de Privilégios" engloba proposições com conteúdo específico que discorre sobre a maior eficiência e efetividade dos gastos governamentais, seja pela redução dos privilégios vinculados aos cargos eletivos ou de carreira no Governo e Estado (salários, gratificações, verbas de gabinete, entre outros) ou, em sentido maior de mudança, prevê a extinção do Fundo Partidário. Já a categoria "Capacitação e Transparência" condensa as diversas proposições, substantivas ou procedimentais, que discorrem sobre a construção de uma equipe com profissionais capacitados, o predomínio de um quadro técnico de especialistas e, paralelamente, o aumento da accountability governamental, que auxiliam no processo de tomada de decisões e viabilizam a estruturação de relatórios mais precisos e significativos sobre as receitas, despesas e contratos em todos os níveis de governo.

Por "Liberalismo Econômico" compreendemos, exclusivamente, as proposições com medidas que garantem as liberdades individuais, face a uma maior responsabilidade fiscal e viabilizam práticas do liberalismo econômico seja pela redução do papel do Estado ao mínimo possível ou por medidas que incentivam a livre iniciativa e a abertura comercial (BresserPereira, 2017). A categoria "Sistema Político" é responsável por compreender proposições que defendem a efetiva descentralização fiscal, política e administrativa do país, ressaltando sua centralidade como mecanismo de atuação do poder público na solução de problemas e especificidades regionais. Sendo assim, apoiando medidas que otimizem o processo burocrático de tramitação de documentos e serviços nas relações entre poder público e cidadãos.

A categoria "Tributação" abrange proposições com um conteúdo específico sobre a simplificação da carga tributária, diante de um cenário favorável ao aperfeiçoamento do sistema de arrecadação e distribuição de receitas e contrário à criação ou ao aumento de impostos. $\mathrm{O}$ vínculo entre as categorias de análise e os compromissos programáticos assumidos no Estatuto pode ser observado, sinteticamente, no Quadro 1 a seguir, através das diretrizes do Termo de Compromisso Partidário e Atuação Legislativa ${ }^{7}$ do partido.

\footnotetext{
${ }^{7} \mathrm{O}$ art. $100^{\circ}$ do Estatuto do partido NOVO atribui os deveres do candidato e expressa em seu inc. IV o dever de assinar e cumprir o Termo de Compromisso Partidário conforme disposto anteriormente no "Art. $6^{\circ}$ - $\mathrm{O}$ pedido de filiação partidária deverá ser efetuado no sitio eletrônico do partido, por intermédio de preenchimento do Formulário de Filiação, da aceitação do Termo de Compromisso Partidário, do Código de Conduta Partidário e do pagamento da contribuição partidária" deste e nos termos de modelo a ser expedido pelo Diretório Nacional. Isso posto, o Termo de Compromisso Partidário é um documento anexo ao Estatuto, previsto e responsável por sintetizar as diretrizes programáticas presentes no Estatuto.
} 
Quadro1 - Estruturação e descrição de categorias

\begin{tabular}{|c|c|}
\hline Categoria & Compromisso expresso do Estatuto do partido NOVO \\
\hline $\begin{array}{l}\text { 1. Gestão de } \\
\text { Políticas Públicas }\end{array}$ & $\begin{array}{l}\text { I - Estabelecer metas e planejamento nas áreas de saúde, educação e } \\
\text { infraestrutura, tão mensuráveis quanto possíveis, para alcançar } \\
\text { resultados de curto, médio e longo prazos. }\end{array}$ \\
\hline $\begin{array}{l}\text { 2.Redução de } \\
\text { Privilégios }\end{array}$ & $\begin{array}{l}\text { II - Trabalhar em prol do cidadão, visando a extinção do fundo } \\
\text { partidário, a redução de privilégios, a diminuição dos custos do Estado. }\end{array}$ \\
\hline $\begin{array}{l}\text { 3.Capacitação e } \\
\text { Transparência }\end{array}$ & $\begin{array}{l}\text { III - Constituir a sua equipe com profissionais capacitados, observando } \\
\text { critérios técnicos para contratação, com a realização de processos } \\
\text { seletivos e com o acompanhamento e o suporte do Departamento de } \\
\text { Apoio ao Mandatário; } \\
\text { IV - Instituir, propor e apoiar ações que viabilizem a transparência } \\
\text { pública e informações sobre arrecadação de receitas, alocação de } \\
\text { recursos, pagamentos e contratos do Poder Legislativo e do Poder } \\
\text { Executivo. }\end{array}$ \\
\hline $\begin{array}{l}\text { 4.Liberalismo } \\
\text { Econômico }\end{array}$ & $\begin{array}{l}\mathrm{V} \text { - Instituir, propor e apoiar medidas que incentivem e garantam, a } \\
\text { responsabilidade fiscal, as liberdades individuais, o empreendedorismo, } \\
\text { a livre concorrência e, sempre que possível, a transferência de } \\
\text { atividades exercidas pelo poder público para o setor privado. }\end{array}$ \\
\hline 5.Sistema Político & $\begin{array}{l}\text { VI - Propor, defender e propugnar medidas que visem a efetiva } \\
\text { descentralização fiscal, política e administrativa do país, visando a } \\
\text { implementação de um Estado efetivamente federativo, que respeite as } \\
\text { diversidades regionais e os interesses do cidadão; } \\
\text { VII - Trabalhar em prol do cidadão, contra projetos ou medidas que } \\
\text { tenham por resultado prático a criação, aumento ou manutenção da } \\
\text { burocracia, ingerência do poder público na vida dos cidadãos. }\end{array}$ \\
\hline 6.Tributação & $\begin{array}{l}\text { VII - Instituir, propor e apoiar projetos ou medidas que tenham por } \\
\text { resultado prático a simplificação da carga tributária. }\end{array}$ \\
\hline 7.Outros & $\begin{array}{l}\text { Assuntos diversos que não se enquadram entre as prioridades } \\
\text { programáticas expressas no Estatuto do partido NOVO. }\end{array}$ \\
\hline
\end{tabular}

Fonte: Elaboração própria a partir do Termo de Compromisso Partidário e Atuação Legislativa do partido NOVO, Título III - Atuação dos Mandatários, art. $7^{\circ}$.

\section{Dados e Discussões}

O trabalho de coleta de dados após a definição de métodos e procedimentos de análise fora realizado diretamente no site do Sigalei, considerando todas as proposições dos oito deputados eleitos pelo partido NOVO para o mandato de 2019 na Câmara dos Deputados: Adriana Ventura; Alexis Fonteyne; Gilson Marques; Lucas Gonzalez; Marcel Van Hattem; Paulo Ganime; Tiago Mitraud e Vinicius Poit. A plataforma digital fornece todas as proposições dos deputados federais, como também ferramentas facilitadoras para busca e refinamento de dados, juntamente com uma avaliação prévia dos eleitos em seu painel de perfil principal que 
consta de cinco abas, denominadas: visão geral; estratégia; produção legislativa; votações e legislatura.

Nosso estudo debruçou-se sobre a área de produção legislativa de cada um dos deputados sobre a qual foi possível buscar todas as proposições do primeiro ano de mandato de 2019. Em uma análise secundária e referencial, ainda consideramos as informações contidas na aba de visão geral dos deputados, presentes no site do Sigalei, sobre a qual podemos verificar um painel geral de resumo sobre cada um dos eleitos, servindo como conferência ao conjunto de proposições verificadas. Por fim, no sentido de produzir maior confiabilidade e refinamento do banco de dados em análise, consultamos a produção legislativa de cada deputado diretamente no site da Câmara dos Deputados, contrastando-as com as verificadas juntos ao site do Sigalei.

Deste modo, nosso universo amostral de dados reune 438 proposições dos oito deputados federais do partido NOVO distribuídas entre substantivas e procedimentais. Conforme o trabalho de Mancuso (2014) as proposições substantivas carregam mérito capaz de modificar o status quo jurídico após específica tramitação e aprovação pelas casas legislativas, expressas por Projetos de Lei, Propostas de Emenda à Constituição, Projeto de Decreto Legislativo, Projeto de Resolução e; por sua vez, as proposições procedimentais tratam de requerimentos diversos voltados à instrução e definição da tramitação que antecedem e conformam as substantivas, tais como requerimentos de urgência, de retirada de pauta, de adiamento de discussão, de concessão de prazo para votação, entre outros.

Observadas as características definidores de cada um dos grupos, não devemos refutar ou diminuir a importância do papel desempenhado pelas proposições procedimentais. Em suma, mesmo que não modifiquem os direitos e deveres inseridos nos marcos legais, exercem impacto fundamental sobre $\mathrm{o}$ andamento das votações substantivas ${ }^{8}$ e na definição das temáticas priorizadas pelos parlamentares. Sendo assim, este trabalho desenvolve a análise de conteúdo tanto das proposições substantivas quanto das procedimentais, na busca de uma maior compreensão sobre congruência entre conteúdo programático e ações legislativas, via formação de agenda por proposições.

No quadro abaixo a análise de alinhamento ${ }^{9}$ tanto com o partido quanto com o governo, em votações com recomendações, corrobora com o argumento de Figueiredo e Limongi $(1995)^{10}$ que mostra um plenário disciplinado e deputados que, na grande maioria das votações, seguem a orientação de seu líder, fora realizada pela plataforma Sigalei e consta na aba de visão

\footnotetext{
${ }^{8}$ Para Mancuso (2014) as votações substantivas ocorrem quando os parlamentares avaliam o mérito de proposições legislativas integrais, de emendas às proposições, ou ainda de trechos que são destacados para votação em separado. Por outro lado, as votações procedimentais, tratam de requerimentos que antecedem as votações substantivas e desempenham papel central e definidor sobre o andamento das votações substantivas.

${ }^{9}$ O Sigalei calculou os dados de alinhamento a partir da observação do posicionamento dos legisladores em todas as votações realizadas no ano de 2019.

${ }^{10}$ Figueiredo e Limongi (1995a:505), "a visão tradicional, segundo a qual os partidos brasileiros são pouco coesos, não encontra sustentação nos dados". Figueiredo e Limongi (1995a:516), "os partidos políticos apresentam grau de coesão interna suficiente para tornar a ação do plenário previsível".
} 
geral de cada candidato. Assim, segue a representação de forma explicativa do número efetivo de proposições de cada candidato.

Quadro 2 - Número total de proposições do partido NOVO

\begin{tabular}{|l|c|c|c|c|c|}
\hline \multirow{2}{*}{ Deputado Federal } & \multicolumn{2}{|c|}{ Proposições (em número) } & \multicolumn{2}{c|}{ Alinhamento } \\
\cline { 2 - 6 } & Procedimental & Substantiva & Total & $\begin{array}{c}\text { Com o } \\
\text { Partido (\%) }\end{array}$ & $\begin{array}{c}\text { Com o } \\
\text { Governo (\%) }\end{array}$ \\
\hline Adriana Ventura & 23 & 16 & 39 & 98 & 90 \\
Alexis Fontayne & 39 & 55 & 94 & 97 & 89 \\
Gilson Marques & 12 & 29 & 41 & 96 & 88 \\
Lucas Gonzalez & 28 & 49 & 77 & 97 & 89 \\
Marcel Van Hattem & 8 & 22 & 30 & 97 & 89 \\
Paulo Ganime & 16 & 40 & 56 & 98 & 88 \\
Tiago Mitraud & 19 & 28 & 47 & 97 & 87 \\
Vinicius Poit & 19 & 35 & 54 & 97 & 90 \\
\hline TOTAL & 164 & 274 & 438 & \multicolumn{2}{|c}{} \\
\cline { 1 - 5 }
\end{tabular}

Fonte: Elaboração própria a partido de dados coletados no site do Sigalei, 2019.

Ressaltamos que o total de 438 casos verificados foram obtidos considerando apenas as proposições dos deputados como autor principal, evitando a dupla contagem. Deste total, a grande maioria das proposições são substantivas, $62,56 \%$ do total de verificado (274 proposições), e expressam conteúdo substancial e de mudança em sua estrutura jurídicolegislativa, manifestadas majoritariamente por Projetos de Lei e Emendas à Constituição.

Ademais, as outras 164 proposições, 37,44\% do total de casos, foram identificadas como procedimentais, expressas por requerimentos com conteúdo específico, seja: pela criação de comissão especial, principalmente para projetos específicos de saúde, educação e gestão de recursos; na convocação de especialistas para participar de seminários e em comissões especiais nas áreas de saúde, educação e economia; pela realização de sessão solene e de congratulações; por requerimentos de urgência em votação, em proposições relacionadas às Reformas Eleitorais ou à redução de gastos do Estado, como extinção do fundo partidário e na redução de privilégios dos parlamentares; por requerimentos de retirada de pauta de temas que já possuem tramitação corrente pelas casas legislativas; por requerer audiência pública em debates sobre temas relacionados à situação fiscal e marcos regulatórios, ao orçamento público e a mobilização de recursos para infraestrutura, tecnologia e fiscalização; entre outros, que aprovisiona conteúdo significativo e fornece argumentos para categorização.

O posterior refinamento de dados fora condicionado observando o perfil característico e as especificidades de cada um dos dois tipos de proposições. As proposições substantivas, devido ao seu perfil de mudança jurídico-legal, foram submetidas a uma categorização entre as sete categorias pré-definidas, resultando em valores que indicam um alto nível de congruência 
entre os assuntos prioritários defendidos no Manifesto partidário e no Estatuto do partido NOVO e a formação da agenda legislativa. Paralelamente, para a análise das proposições procedimentais verificamos a frequência dos tipos de requerimentos e, posteriormente, a incidência dos assuntos aos quais se referiram, cujos resultados possibilitam destacar um enquadramento significativo entre as temáticas priorizadas pelos deputados federais do partido e as preferências programáticas verificadas no Manifesto e Estatuto partidário do NOVO e que serviram de suporte para construção das categorias de análise. Tais elementos corroboram com nossa hipótese inicial de que a atuação legislativa do partido NOVO teria um conteúdo ideológico e programático mais bem definido, ou seja, ideologicamente mais claro e consistente.

O Gráfico 1 abaixo demonstra o resultado da divisão das proposições substantivas nas sete categorias de análise, cujo resultado indica uma congruência de 75,18\% distribuídas entre as seis categorias. A categoria Outros, responsável por $24,82 \%$ das proposições, engloba um conteúdo diverso em suas proposições e não expresso dentre as prioridades programáticas do partido NOVO. Entretanto, concentram temas locais e específicos aos deputados, como questões sobre rastreamento e identificação de veículos, ordem específicas de fiança bancária, processos de descriminalização de condutas como injúria e difamação, aprimoramento de medidas protetivas, entre outros.

Gráfico 1 - Frequência das proposições substantivas (por categorias)

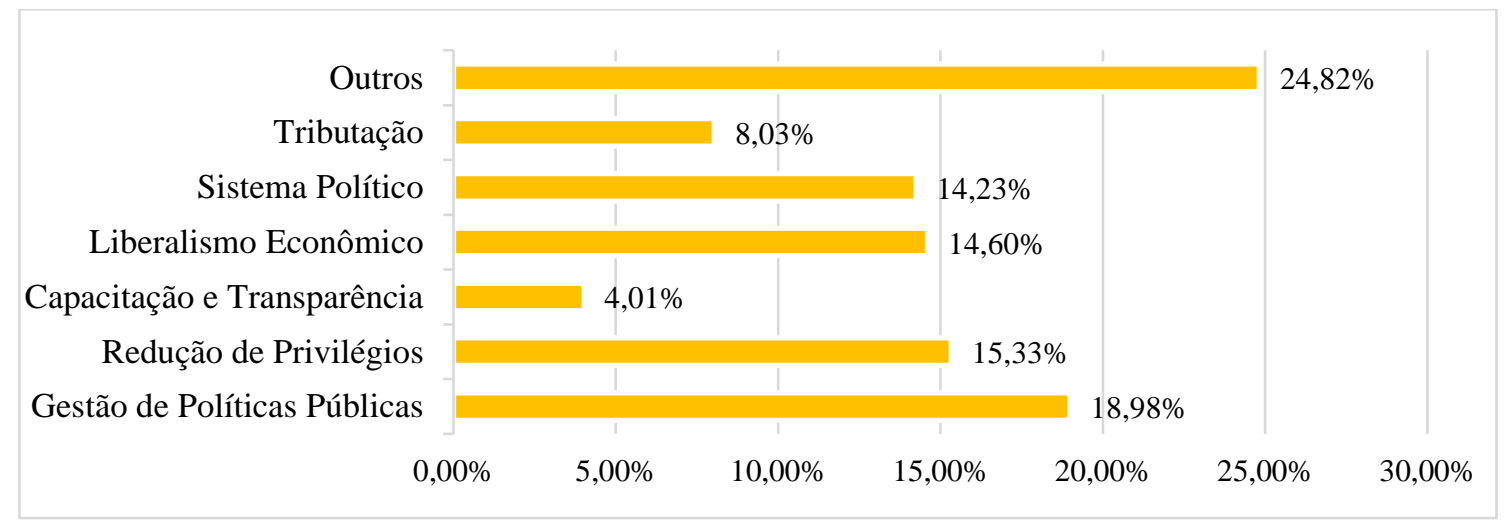

Fonte: Elaboração própria, 2019.

Com maior destaque, cerca de 18,98\%, encontra-se a categoria Gestão de Políticas Públicas. Tal fato refere-se a uma tendência do partido de propor, via Projeto de Lei ou Emenda Constitucional, nas áreas de infraestrutura, assistência à saúde e educação e de reestruturação das matrizes energéticas (petróleo, gás e energia). Esse comportamento indica um alinhamento ao conteúdo programático do partido nessas respectivas áreas, principalmente, por vincular a melhoria da qualidade de vida e o acesso a serviços públicos de qualidade à simplificação dos procedimentos burocráticos e ao aprimoramento da gestão e administração pública. Uma característica essencial deste grupo de proposições seria considerar que sua instrumentalização 
acompanha planos e metas exequíveis a curto, médio e longo prazo e sua reorganização e implementação através de políticas públicas de Governo.

Em segundo lugar, com 15,33\% das proposições, encontra-se a categoria Redução de Privilégios, a qual tem por conteúdo central a maior eficiência e efetividade dos gastos governamentais, seja pela redução ou extinção dos privilégios vinculados aos cargos eletivos ou de carreira no Governo e Estado. São expressas, majoritariamente, por propostas de redução de verbas de assessoria de gabinete, pela extinção de gratificações e por medidas que preveem a extinção do Fundo Partidário. Paralelamente a essa atuação legislativa e em concordância com o conteúdo programático ao qual se refere, medidas procedimentais internas ${ }^{11}$ foram implementadas pelo partido NOVO a fim de reduzir o valor de recursos públicos utilizado por seus parlamentes ao final do primeiro ano de mandato.

Em ordem, a categoria Liberalismo Econômico agrupa 14,60\% dos casos, majoritariamente compostos por proposições com medidas que garantem as liberdades individuais, uma maior responsabilidade fiscal e viabilizam práticas do liberalismo econômico. Nesse sentido, incluem propostas e procedimentos que incentivem o empreendedorismo, a simplificação das leis trabalhistas e viabilizam a transferência de atividades exercidas pelo poder público para o setor privado, seja pela redução do papel do Estado ou por incentivos à livre iniciativa e à abertura comercial.

Já a categoria Sistema Político condensa 14,23\% dos casos analisados e trata exclusivamente de temas associados à descentralização fiscal, política e administrativa do país. Tais proposições, além de compreenderem medidas que procuram otimizar o processo burocrático de tramitação de documentos, ressaltam a ampliação do investimento privado como mecanismos centrais para a efetiva atuação do poder público no combate aos problemas regionais e na distribuição de serviços e atendimento de qualidade aos cidadãos.

Tal como nas arenas anteriores de reformas trabalhistas e fiscais, o menor índice da categoria Tributação, responsável por 8,03\% das proposições, se explica na necessidade de uma tramitação e aprovação específica nas Casas Legislativas (Câmara Federal e Senado) sobre seu tema específico e, concomitante, por possuir grandes projetos de Emendas Constitucionais em processo de circulação por estas casas ao longo do mandato de 2019. Integralmente composta por projetos de lei pela simplificação e diminuição da carga tributária, o menor índice também se justifica pela dificuldade de articulação entre os partidos sobre este determinado tema.

A categoria Capacitação e Transparência, com 4,01\% do total das proposições, expressa de forma clara a prioridade programática do partido e discorrem sobre a construção de equipes

\footnotetext{
${ }^{11} \mathrm{O}$ processo de transparência e a prestação de contas do partido NOVO inclui procedimentos específicos e material detalhado em suas plataformas oficiais. Tal mecanismo prevê além da dispensa do valor referente ao Fundo Partidário - aplicado em banco público e à espera de vias oficiais para devolução ao Estado, uma composição de estudos e relatórios que auxiliam e comprovam a economia de recursos pelo partido na Câmara quanto a diversos segmentos, seja: com a renúncia de benefícios (mudança, moradia e assistência saúde); a alocação eficiente da verba de gabinete (diminuição do quadro de funcionários nos gabinetes); e promovendo a utilização racional da cota parlamentar.
} 
compostas por profissionais capacitados. Portanto, o predomínio de um quadro cada vez mais técnico e especializado no Governo, auxiliaria no processo de tomada de decisões seja contribuindo para a eficiência e eficácia de recursos em políticas públicas ou no desenvolvimento de um efetivo vínculo com os cidadãos por intermédio de uma maior transparência e accountability governamental. Neste caso, a baixa frequência de casos é justificada na medida em que a maioria das proposições legislativas que tratam deste tema configuram-se como procedimentais, e requerem, recorrentemente, a criação de comissões especiais, a convocação de especialistas para discussão em comissões e simplificação e a sistematização dos meios de transparência pública.

A compreensão da particularidade aferida na categoria anterior nos encaminha para a segunda etapa de análise deste trabalho, constituída pelo exame detalhado das proposições procedimentais. O refinamento destas proposições, compostas estritamente por requerimentos, possibilitou sua alocação em quatro grandes tipos de requerimentos: realização de audiência pública; criação de comissão ou subcomissão especial; inclusão de convidados e especialistas em comissões; e uma última, diversos, responsável por agrupar os casos específicos e de baixa frequência. Posteriormente, medimos a incidência dos assuntos aos quais as proposições se referiram os correlacionando às categorias de análise pré-definidas.

A divisão destas proposições acarretou em uma distribuição por frequência de incidência de cada um dos tipos de requerimento conforme o Quadro 3 abaixo. Destacamos que a categoria "Diversos" compreende uma soma de casos compostos por requerimentos que não possuem frequência significativa (menos de $2 \%$ do total de casos) e, portanto, não constituem uma categoria particular. Dentre eles, ressaltamos os requerimentos: de destaque para votação em separado (3 casos); de revisão de despacho (3 casos); de urgência para votação (3 casos); de solicitação de informações (3); de retirada de pauta (2 casos); de inclusão de coautoria em projetos de lei ( 2 casos); de desapensação de projetos de lei (2 casos); entre outros casos de requerimentos diversos, específicos e individuais, voltados à instrução e definição da tramitação.

Quadro 3 - Número de proposições procedimentais por tipos de requerimento

\begin{tabular}{|l|c|c|}
\hline \multicolumn{1}{|c|}{ Tipos de requerimento } & Total de casos (N) & Frequência por tipo \\
\hline Realização de audiência pública & 60 & $36,59 \%$ \\
\hline Criação de comissão ou subcomissão especial & 29 & $17,68 \%$ \\
\hline $\begin{array}{l}\text { Inclusão de convidados e especialistas em } \\
\text { comissões }\end{array}$ & 28 & $17,07 \%$ \\
\hline Diversos & 47 & $28,66 \%$ \\
\hline \multicolumn{1}{|c|}{ Total } & 164 & $100,00 \%$ \\
\hline
\end{tabular}

Fonte: Elaboração própria a partido de dados coletados no site do Sigalei, 2019. 
Diferentemente dos Projetos de Lei e propostas de Emenda à Constituição os requerimentos não possuem a finalidade de mudança da estrutura jurídico-legislativa. Contudo, há decisões procedimentais importantes, sendo que o desenvolvimento de uma análise individual sobre sua matéria viabiliza o enquadramento e associação de cada um dos requerimentos às categorias de análise. Assim, diferentemente da congruência evidenciada na análise anterior sobre as proposições substantivas, essa investigação permite identificar as preferências temáticas que estes dispositivos carregam. O Quadro 4 abaixo apresenta a distribuição entre o cruzamento das 164 proposições procedimentais, orientadas pelas categorias de análise, em cada um dos quatro tipos de requerimentos.

Quadro 4 - Frequência das proposições procedimentais (por categorias)

\begin{tabular}{|c|c|c|c|c|c|c|c|}
\hline \multirow{2}{*}{$\begin{array}{c}\text { Tipos de } \\
\text { Requeriment } \\
\text { o }\end{array}$} & $\begin{array}{c}\text { Gestão } \\
\text { de } \\
\text { Políticas } \\
\text { Públicas }\end{array}$ & $\begin{array}{c}\text { Redução } \\
\text { de } \\
\text { Privilégio } \\
\text { s }\end{array}$ & $\begin{array}{c}\text { Capacitação } \\
\text { e } \\
\text { Transparênci } \\
\text { a }\end{array}$ & $\begin{array}{c}\text { Liberalism } \\
\text { o } \\
\text { Econômico }\end{array}$ & $\begin{array}{c}\text { Sistema } \\
\text { Político }\end{array}$ & $\begin{array}{c}\text { Tributaçã } \\
\text { o }\end{array}$ & Outros \\
\hline $\begin{array}{c}\text { Realização de } \\
\text { audiência } \\
\text { pública }\end{array}$ & $4,27 \%$ & - & $32,32 \%$ & - & - & - & - \\
\hline $\begin{array}{c}\text { Criação de } \\
\text { comissão ou } \\
\text { subcomissão } \\
\text { especial }\end{array}$ & $8,54 \%$ & $0,61 \%$ & $5,49 \%$ & - & $0,61 \%$ & - & $2,44 \%$ \\
\hline $\begin{array}{c}\text { Inclusão de } \\
\text { convidados e } \\
\text { especialista } \\
\text { em comissões }\end{array}$ & $0,61 \%$ & - & $12,80 \%$ & - & - & $0,61 \%$ & $3,05 \%$ \\
\hline Diversos & $1,83 \%$ & $8,54 \%$ & $2,44 \%$ & $0,61 \%$ & $2,44 \%$ & $0,61 \%$ & 12,20 \\
$\%$
\end{tabular}

Fonte: Elaboração própria, 2019.

Observamos a predominância de todos os quatro tipos de requerimentos nas categorias "Capacitação e Transparência" e "Gestão de Políticas Públicas". Nas categorias "Redução de Privilégios", "Liberalismo Econômico", "Sistema Político" e "Tributação" observa-se a baixa frequência ou ausência de valores referente aos tipos de requerimentos. Esse fenômeno, em concordância com a análise anterior sobre as proposições substantivas, é explicado pelo teor de real mudança jurídico-legal que essas categorias carregam, principalmente por tratar de variáveis econômicas e sobre Reformas Estruturais (Partidária, Fiscal e da Previdência) que necessitam de tramitação específica. As características expressas por esses requerimentos contribuem para o processo de tomada de decisão e viabilizam a estruturação de relatórios mais precisos e significativos sobre as receitas, despesas e contratos em todos os níveis de governo, corroborando com a discussão anterior relativa às proposições substantivas. 
Ao representar um conjunto de planos e metas exequíveis pelo Estado no curto, médio e longo prazo, a categoria "Gestão de Políticas Públicas" requer proposições com estrutura e conteúdo que modifica o ordenamento jurídico-legal. Assim, as decisões procedimentais desta categoria, tanto para a criação e inclusão de especialistas em comissões quanto para realização de audiência pública para as áreas de saúde, educação e infraestrutura, apenas auxiliam organicamente o processo corrente que as proposições substantivas se referem. Em contrapartida, a categoria "Capacitação e Transparência" que representa o processo de construção de uma equipe formada por profissionais capacitados, com o predomínio de um quadro técnico de especialistas e, paralelamente, uma efetiva accountability governamental, possui ordem corrente majoritariamente composta por requerimentos. De fato, decisões sobre a realização de Audiência Pública, a criação de Comissão ou Subcomissão Especial e inclusão de especialistas em comissões são expressas por procedimentos, sem a necessidade de mudança dos direitos e deveres inseridos no marco legal, mesmo que carregarem decisões importantes.

De modo geral, constatamos o predomínio de proposições substantivas e em relação às procedimentais, característica que indica a dualidade entre um traço programático bem definido do partido NOVO e a necessidade corrente de requisições no auxílio do exercício de mandato, expressas em proposições que possuem conteúdo significativo de mudança jurídico-legislativa. Ressaltamos as categorias "Liberalismo Econômico" e "Tributação" que em sua quase totalidade foram representadas por proposições substantivas e, em sentido inverso, a categoria "Capacitação e Transparência", que inclui em sua maioria proposições procedimentais, com um conteúdo que prioriza a formação de Comissões constituídas por especialistas, o aumento significativo de Audiências Públicas temáticas com e a utilização de mecanismos e ferramentas tecnológicas para aprimoramento do banco de dados governamental, auxiliando no aumento da transparência.

Em caráter exploratório, evidenciamos que houve, no período em análise, um projeto paralelo de Reforma Eleitoral e de Reforma da Previdência nas Casas Legislativas, explicando o menor número de proposições sobre esse tema, face a necessidade de mudanças estruturais substantivas via Reformas. Como segunda variável explicativa, enfatizamos a gestão e transparência interna de recursos dos deputados do partido NOVO, simultâneas às proposições apresentadas que objetivam diminuir privilégios e o custo do Estado, por uma melhor gestão de recursos públicos.

\section{Conclusões}

Considerando o pressuposto de que os princípios democráticos asseguram uma maior representação, consideramos o argumento de Manin, Przerworski e Stokes (1999) de que nas democracias recentes necessitam de instituições eleitorais que aumentem a transparência da responsabilidade e facilitem a escolha dos eleitores quanto à identificação de programas e 
agenda mais definidos aos partidos. Assim, nossas observações fornecem indicativos positivos ao debate que vincula os programas partidários como um preâmbulo de uma futura agenda governamental.

Os resultados observados indicam significativa congruência entre saliência programática do partido NOVO e a agenda legislativa de seus respectivos deputados federais, quanto as proposições substantivas. Concomitantemente, em decorrência da avalição das proposições procedimentais destacamos um enquadramento significativo entre as temáticas priorizadas pelos deputados federais do partido e as preferências programáticas verificadas no Manifesto e Estatuto partidário do NOVO. Evidenciamos que o termo agenda legislativa deve contemplar os compromissos assumidos durante a disputa eleitoral e, deste modo, a avaliação de sucesso do mandato ou de funcionalidade do sistema político brasileiro poderia abarcar outras dimensões para além da exposta nesta proposta, como por exemplo, a congruência entre promessas de campanha e ações governamentais, explorando as propagandas e programas de governo.

Além de identificar os temas considerados prioritários pelos deputados federais, os associando com o conteúdo programático do partido, este trabalho fornece variáveis que auxiliam na análise sobre responsividade dos eleitos perante o eleitorado e em futuros estudos de congruência partidária, definição de agenda e comportamento legislativo. Assim, retomando o argumento de Mayhew (1974) de que apenas a apresentação de proposições não representa um esforço efetivo de mobilização de agenda, não podemos inferir em que medida houve uma mobilização para cumprir as promessas expressas nos programas partidários. Contudo, os resultados aqui apresentados contribuem como variáveis explicativas na análise futura deste fenômeno e sugerem que os partidos podem, de fato, influenciar a agenda legislativa.

A mobilização de uma agenda passa por outras atividades que exigem esforço político, considerando a influência de outros fatores endógenos e exógenos ao partido NOVO, como lutar pela aprovação das proposições em comissões e plenário, o que passa por conseguir atenção das lideranças, participar de reuniões, mobilizar campanhas cívicas e midiáticas, entre outros. Portanto, novos estudos, por exemplo, poderiam verificar o efeito da atenção às questões nas agendas políticas formais, incluindo a análise de possíveis efeitos sobre a legislação principal e a atenção à política por nomeados políticos na burocracia (CARREIRÃO, 2015).

Por fim, nossos resultados podem indicar uma predição de agendas legislativas através da análise das plataformas partidárias, considerando-as como como variáveis dependentes. Nesse sentido, seria conveniente explorar modos de operacionalizar acertadamente variáveis como o tamanho do partido, o contexto em que nasce, os tipos de eleições internas que existem e o tipo de liderança, e investigar sua incidência sobre a coerência partidária. Tal argumento permite ampliar nossa compreensão sobre o processo de representação e a busca de novas 
variáveis explicativas da coerência partidária, tanto no âmbito institucional quanto programático no processo de investigação de coerência partidária.

\section{Referências}

ALDRICH, John. Why Parties? A second Look. Chicago; London: University of Chicago Press, 2011.

BARDIN, Laurence. Análise de conteúdo. Lisboa: Edições 70, 2002.

BAUMGARTNER, Frank. R.; JONES, Bryan. D. Agendas and Instability in American Politics. Chicago: University of Chicago Press, 1993.

BRASIL. Câmara dos Deputados. Pesquisa simplificada. Disponível em: https://www.camara.leg.br/buscaProposicoesWeb/pesquisaSimplificada. Aceso em: 5 jan. 2020.

BRESSER-PEREIRA, Luiz Carlos. Como sair do regime liberal de política econômica e da quase-estagnação desde 1990. Estudos Avançados, v. 31, n. 89, 2017.

CARRERÃO, Yan. S. Representação política como congruência entre as preferências dos cidadãos e as políticas públicas: uma revisão da literatura internacional. Opinião Pública, v. 21, n. 2, p. 32-41, 2015.

CHIZZOTTI, Antonio. Pesquisa qualitativa em ciências humanas e sociais. Petrópolis: Vozes, 2006.

COPPEDGE, Michael. The dynamic diversity of Latin American party systems. Party Politics, n. 4, p. 547-568, 1997.

DAHL, Robert. Poliarquia. Participação e Oposição. São Paulo: EDUSP, 2015.

DIAMOND, Larry; HARTLYN, Jonathan; LINZ, Juan. J.; LIPSET, Seymour. M. Democracy in developing countries. Latin America. Boulder, Colorado, Lynne Rienner Publishers, 1999.

DOWNS, Anthony. An economic theory of democracy. Nova York: Harper and Row, 1957.

EGAN, Patrick. J. Partisan Priorities: How Issue Ownership Drives and Distorts American Politics. Cambridge: Cambridge University Press, 2013.

FAGAN, Edward. J. Marching Orders? U. S. Party Platforms and Legislative Agenda Setting 1948 - 2014. Political Research Quarterly, v. 71, n. 4, p. 949-959, 2018.

FIGUEIREDO, Arlegina; LIMONGI, Fernando. Partidos Políticos na Câmara dos Deputados: 1989 - 1994. Dados, v. 38, n. 3, p.43-61, 1995a.

HOFFERBERT, Richard. I.; BUDGE, Ian. The Party Mandate and the Westminster Model: Election Programmes and Government Spending in Britain, 1945-1985. British Journal of Political Science, v. 22, n. 2, p. 151-182, 1992.

MADEIRA, Rafael; TAROUCO, Gabriela. Esquerda e direita no Brasil: uma análise conceitual. Revista Debates, v. 7, n. 2, p. 93-114, 2013. 
MANCUSO, Wagner Pralon. A regra e as exceções: líderes partidários e casos desviantes na relação Executivo-Legislativo. In: DANTAS, Humberto; TOLEDO, José Roberto; TEIXEIRA, Marco Antonio Carvalho (org.). Análise política e jornalismo de dados: ensaios a partir do basômetro. Rio de Janeiro: Editora FGV, p.183-202, 2014.

MANIN, Bernard; PRZEWORSKI, Adam; STOKES, Susan. Introduction. In: PRZEWORSKI, Adam; STOKES, Susan; MANIN, Bernard (ed.). Democracy, accountability, and representation. Cambridge: Cambridge University Press, p. 1-26, 1999.

MANIN, Bernard; PRZEWORSKI, Adam; STOKES, Susan. Eleições e representação. Lua Nova, n. 67, p. 105-138, 2006.

MAYHEW, David. Congress: The Electoral Connection. New Haven: Yale University Press, 1974.

PETROCIK, John. R. Issue Ownership in Presidential Elections, with a 1980 Case Study. American Journal of Political Science, n. 40, p. 825-850, 1996.

RODRIGUEZ, Leticia. M. R.; MONTERO, Mercedes. G. Coerência Partidária nas elites parlamentares latino americanas. Opinião Pública, v. 8, n. 2, p. 189-229, 2002.

SIGALEI. Painel Principal. Disponível em: https://web.sigalei.com.br/app/mainPanel. Acesso em: 5 jan. 2020.

STROM, Kaare; MÜLLER, Wolfgand. Political parties and hard choices. In: MÜLLER, Wolfgand; STROM, Kaare (ed.). Policy, office or votes? How political parties in Western Europe make hard decisions. New York: Cambridge University Press, p. 1-35, 1999.

Artigo recebido em: 2020-02-06

Artigo reapresentado em: 2020-05-10

Artigo aceito para publicação em: 2020-05-19 